\title{
Multi-phase Flow Simulations in Direct Iron Ore Smelting Reduction Process
}

\author{
Hsin-Chien CHUANG, ${ }^{1)}$ Jer-Haur KUO, ${ }^{1)}$ Chien-Chia HUANG, ${ }^{1)}$ Shih-Hsien LIU ${ }^{2)}$ and Weng-Sing HWANG ${ }^{1)}$ \\ 1) Department of Materials Science and Engineering, National Cheng Kung University, No. 1 Ta-Hsueh Road, Tainan 701, \\ Taiwan, R.O.C. E-mail: angi@mail.mse.ncku.edu.tw $\quad$ 2) Iron Making Process Development Section, Steel \& Aluminum \\ Research \& Development Dept., China Steel Corporation, No. 1 Chung Kang Road Hsiao Kang, Kaohsiung 81233, Taiwan, \\ R.O.C.
}

(Received on December 12, 2005; accepted on June 7, 2006)

\begin{abstract}
The purpose of this study is to develop a computer simulation system to analyze the multi-phase (gas-liquid-slag) flow phenomena in the direct iron ore smelting reduction vessel to evaluate the conditions of stirring and mixing induced by bottom gas-blowing.

A computational fluid dynamics technique, called the SOLA-VOF method, has been used to treat the flow behavior of molten iron with free surface. As to the issue of the multi-phase, the Langrange and the QuasiSingle Phase concept were applied to analyze the flow behavior of injected gas, molten iron, and slag. The simulation system can be directly applied to analyze stirring processes at high flow rate gas and its related turbulent free surface.

The developed system was then applied to analyze the flow behavior in the $60 \%$ Experimental Smelting Reduction Vessel (ESRV). Interactions between injected gas and liquid bath, agitation of slag and mixing conditions of liquid bath and slag under different gas flow rates, bubble sizes, and arrangements of bottomblown tuyeres were evaluated in this study. The simulation results were then compared with water model experiments under similar flow conditions and were found to closely correspond with the experimental results.
\end{abstract}

KEY WORDS: mathematical modeling; multi-phase flow; ironmaking process; smelting reduction vessel; gas stirring treatment; volume of fluid method.

\section{Introduction}

Several new processes for iron-making which included Direct Iron Ore Smelting (DIOS), HIsmelt, Romelt, AISI, AUSmelt have been developed in recent years. ${ }^{1,2)}$ The core technology of processes mentioned above is a directly smelting and reduction process which iron is reduced directly by using iron ore and coal that needn't to be pretreated via sintering and coking process. It can not only economize energy but also reduce environmental pollutions.

There are many traditional metallurgical processes where the liquid phase contained in a furnace is agitated by gas stirring such as ladle and the secondary refining of aluminum and copper. As well as the direct smelting reduction process in ironmaking, the high flow rate gas (such as $\mathrm{N}_{2}$ or Ar) is blown from tuyeres at the bottom of furnace through the liquid in order to enhance mixing, to promote chemical reaction efficiency between iron bath and slag, and to improve the temperature and chemical homogeneity of the molten iron. Therefore, the characteristics of the process have highly turbulent free surface and strongly exchange of mass and momentum among gas bubbles, iron bath and molten slag. In order to investigate how transfer phenomenon affects the efficiency of iron-making process, scientists employ hot model experiments, water model experiments and numerical simulation technologies to analyze heat and mass transfer phenomenon in the smelting reduction process.

For the two phase flow problem of gas injection induced stirring phenomena, main numerical methods were summarized by Mazumdar and Guthrie. ${ }^{3)}$ These can be divided into three methods: Continuous Phase Method, Discrete Phase Method, and Quasi-Single Phase Method.

The first method for treating two phase flow problem is named "Continuous Phase Method", which is also called "Eulerian Two Phase Method". In the method, the liquid and gas phases are considered to be two different continuous fluids, which are separated by sharp (but flexible) boundaries and are interacting with each other through the finite inter-phase areas.

The second method for treating two phase model is "Discrete Phase Method" also called "Lagrangian Two Phase Method". In Discrete Phase Method, liquid and gas are treated as different flow fluid respectively. The size and volume fraction of two phase region are calculated by the number and position of gas bubbles.

The third method is "Quasi-Single Phase Method".,5) In earlier studies, the size and shape of the plume zone where molten iron and gas bubbles coexist as well as the shearing 
force of the plume zone on the remaining molten iron zone where only molten iron exists had been assumed/prescribed. Fluid-dynamics principles for the pure liquid were applied in the liquid zone to calculate the induced velocity field of the molten iron. Then, improvements were made to alleviate the necessity of prescribing the plume zone. ${ }^{6)}$ In these studies, the complete furnace system, including the plume zone and the pure liquid zone, was considered simultaneously. A quasi-single phase model was usually employed to treat the two-phase system. The fluid in the system was considered to have only one phase, which is the mixture of gas and molten iron. A parameter, called liquid fraction - which is the percentage of a control volume occupied by liquid, was used in the model so that one set of fluid dynamics equations was enough to describe the flow behaviors in the plume zone where gas and molten iron coexist and in the liquid zone where only molten iron exists.

Several computational fluid-dynamics techniques that have the capability to treat the gas/liquid interface problem have been applied to simulate numerically the gas/liquid interaction in the gas stirred system. The techniques include the volume-of-fluid (VOF) method, the front tracking method, the projection method, and the marker-and-cell (MAC) method. ${ }^{7,8)}$ While these studies succeeded in simulating the gas/liquid interactions when large bubbles are involved, they were, however, limited to the cases where only one or small amount of bubbles are floating in the vessel.

The purpose of this study was to develop a mathematical model capable of numerically simulating the multi-phase fluid-flow phenomenon in the gas-stirring operation of the direct smelting reduction process in ironmaking and to verify experimentally the reliability of this mathematical model with a water model. In this study, the multi-phase flow system including gas bubbles, molten iron, and slag was treated simultaneously by the quasi-single-phase model. The essence of the MAC technique was employed to treat the gas/liquid and liquid/slag interface problems. The VOF method was used to treat highly turbulent free surface at the top of liquid bath due to the high blowing flow rate in the direct smelting reduction process. Three-dimensional cases were considered. The concerned multi-phase fluid flow included how the flotation of released bubbles induce the molten iron and slag to flow, how the shapes of the plume zone and free surface vary during the flotation under the influence of the molten iron flow, and how the various bubbles interact with others. Finally, the mixing phenomena with respect to the various stirring conditions, such as gas flow rate, number and position of bottom-blowing tuyeres, initial height of liquid, and bubble diameter in the numerical-simulation model was discussed.

\section{Mathematical Model}

\subsection{Description of Physical Phenomena}

The gas stirring treatment is essentially a gas-bubbledriven recirculation flow system. When gas is released from the tuyere, it forms large gas bubbles. Owing to the density difference, the gas bubbles tend to flow to the top. As they float, they induce the molten iron and slag to flow, and in turn the flowing melt affects the flow patterns of the rising bubbles as well as slag. Then the gas bubbles rapidly break through the floating slag due to the large flow rate gas and continuous blowing. Analysis of the phenomena is a fairly complex fluid mechanics problem. It was the purpose of this study to be able to simulate these phenomena.

A set of first kind makers is introduced in the system to represent the introduction of the gas bubbles. Then another set of makers of a second kind is used in the system to represent the slag floating on the top of molten iron. The next step is to solve the partial differential equations that describe the fluid-flow behaviors of the fluid in each cell of the system. In this study, the solution of velocity and pressure fields was based on SOLA (SOLution Algorithm) scheme, and free surface was tracked by using the VOF method. It should be noted that the cells may contain only liquid, only gas, only slag, a mixture of gas/liquid, a mixture of slag/liquid, a mixture of gas/slag, or a mixture of gas/liquid/slag. In this study, a parameter called density function was incorporated in the partial differential equations to make the same set of equations applicable to all the elements.

\subsection{Governing Equations of Quasi-single Phase Model}

As described earlier, the phenomena discussed here is basically a three-phase fluid-flow problem. However, only one set of governing equations is used to describe its fluidflow behavior by employing a density function in the equations. The forms of the equations are as follows:

Continuity Equation:

$$
D=\frac{\partial U_{i}}{\partial x_{i}}=0
$$

Momentum Equation:

$$
\begin{aligned}
& \rho\left[\frac{\partial U_{i}}{\partial t}+U_{j} \frac{\partial U_{i}}{\partial x_{j}}\right] \\
& \quad=-\frac{\partial P}{\partial x_{i}}+\frac{\partial}{\partial x_{j}} \mu\left[\frac{\partial U_{i}}{\partial x_{j}}+\frac{\partial U_{j}}{\partial x_{i}}\right]+\rho g_{i}
\end{aligned}
$$

where $D$ is divergence; $U_{i}$ is velocity of the marker in the $x_{i}$ direction, $P$ is pressure; $\rho$ is the density of the control element; $\mu$ is viscosity

$$
\rho=\rho_{\mathrm{g}} f_{\mathrm{g}}+\rho_{\mathrm{l}} f_{\mathrm{l}}+\rho_{\mathrm{s}} f_{\mathrm{s}}
$$

where $\rho_{\mathrm{g}}, \rho_{\mathrm{l}}, \rho_{\mathrm{s}}$ are the density of gas bubble, liquid iron, and molten slag, respectively; $f_{\mathrm{g}}, f_{\mathrm{l}}, f_{\mathrm{s}}$ are the volume fraction of gas, liquid, and slag, respectively. The particles for representing of the gas, liquid, and slag can be calculated and traced to judge whether the cell is occupied by them in every time step. In this study, the volume fraction of $f_{\mathrm{g}}, f_{\mathrm{l}}, f_{\mathrm{s}}$ are given in seven conditions and listed in Table $\mathbf{1 .}$

\subsection{Treatment of Gas Bubble and Slag Movement}

As the velocity of each cell is calculated, the velocity for a gas marker or a slag marker is then interpolated from these cell velocities. The gas markers are moved according to their velocities and the slag markers are moved according to their velocities coupled with buoyancy force, then a new flow condition is realized. The flow condition includes the 
Table 1. Conditions for the volume fraction of gas, liquid, and slag

\begin{tabular}{|c|ccccccc|}
\hline$f_{g}$ & $1 / 3$ & $1 / 2$ & $1 / 2$ & 0 & 0 & 0 & 1 \\
$f_{l}$ & $1 / 3$ & $1 / 2$ & 0 & $1 / 2$ & 0 & 1 & 0 \\
$f_{s}$ & $1 / 3$ & 0 & $1 / 2$ & $1 / 2$ & 1 & 0 & 0 \\
\hline
\end{tabular}

velocity of the molten iron as well as the positions and shapes of the gas bubbles and slag. By the gas-stirring rate and the bubble-formation rate, serious bubbles are formed later. Then, a set of markers of the following kind is introduced to represent its existence. The procedures are repeated until the flow system reaches its steady state.

\subsection{Treatment of the Free Surface}

In order to simulate a highly turbulent free surface at high gas blowing rate in the direct smelting reduction vessel, the location of free surface has to be estimated first. Then the change of free surface with time is calculated therefore the evolution of the fluid domain is computed. In this study, the VOF method developed by Hirt and Nichols ${ }^{8)}$ was adopted to present the fluid domain and to track the evolution of its free boundaries. The piecewise linear interface calculation (PLIC) method developed by Youngs ${ }^{9)}$ was also adopted in this study to yield a more accurate interface approximation than the simple line interface calculation (SLIC) method.

\section{Numerical Method}

The flow equations described in the previous section are a set of nonlinear partial differential equations that are difficult to solve by analytical methods. Therefore, they must be solved by numerical methods.

In the present study, a computational fluid dynamics scheme called the SOLA method was used to solve the flow equations. The system was first divided into a number of rectangular cells. The SOLA scheme, which was improved and extended from the MAC technique, used an explicit finite-difference method with pressure $\mathrm{p}$ and velocity components $\mathrm{U}, \mathrm{V}$, and $\mathrm{W}$ as the primary dependent variables. Numerical procedures were carried out to solve the time-dependent incompressible fluid flow equations and the turbulence equations simultaneously with the imposed wall and free boundary conditions using the VOF method.

\section{Test Results and Discussions}

In this study, a 3D mathematical model has been developed to simulate numerically the interactions among the gas bubbles, molten iron and slag during the bottom gasblowing induced stirring and mixing. To demonstrate how the model could aid the engineers to analyze multi-phase (gas-liquid-slag) flow phenomena in the direct smelting reduction vessel, a water model with $60 \%$ size of an experimental smelting reduction vessel (ESRV) was employed in this study.

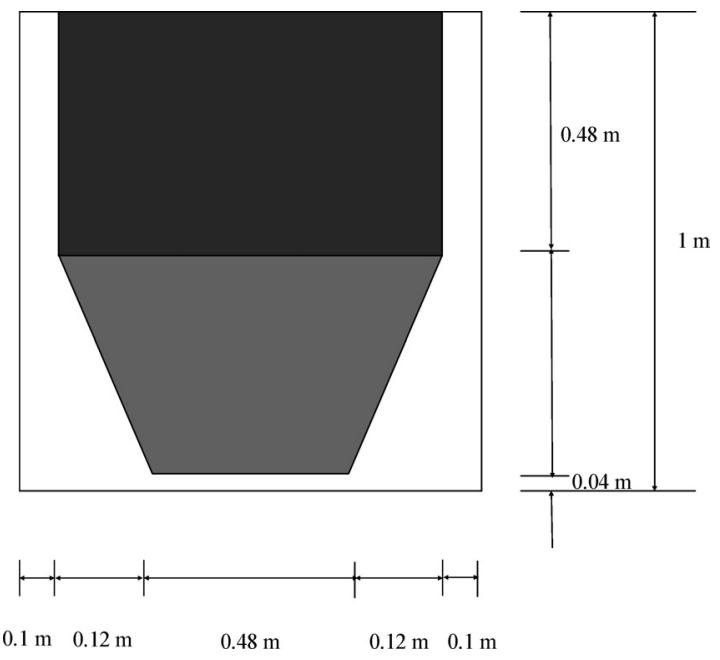

Fig. 1. The model of the $60 \%$ reduced experimental smelting reduction vessel.

\subsection{Case Simulation and Its Experimental Verification}

In this study, the water model was established to simulate the flow pattern in ESRV. Water was used to replace molten iron while acrylic glass was used to construct the vessel of water model for direct observation of flow patterns. The acrylic vessel could be divided into two parts as shown in Fig. 1: the upper part is $0.72 \mathrm{~m}$ in diameter and $0.48 \mathrm{~m}$ in height, the lower part is a cone with diameter from $0.48-0.72 \mathrm{~m}$ and $0.48 \mathrm{~m}$ in height. There were $3-5$ tuyeres at the bottom of the acrylic vessel as the gas inlets. Also, the geometry of simulation model was established according to this acrylic vessel.

To verify the mathematical model developed in this study, the results of the simulation need to be validated by experimental observations. The densities of the liquid and the gas were taken to be 1.0 and $0.0012 \mathrm{~g} \mathrm{~cm}^{-3}$, respectively. The liquid was filled up to $48 \mathrm{~cm}$ high above the bottom of the vessel. Initial bubble diameter was $2 \mathrm{~cm}$. There were 5 bottom-blown gas tuyeres designed in this study. As shown in Fig. 2, the simulation results are similar to experimental results under gas flow rate of $2000 \mathrm{~cm}^{3} \mathrm{~s}^{-1}$.

As the mathematical model is approved via the water model experiment, the following sections will show the simulation results under different number and positions of bottom-blown gas tuyeres, different gas flow rates, different height of initial iron bath surface, and different diameter of blowing gas bubble.

\subsection{Gas/Liquid/Slag Interactions under Different Bot- tom-blown Tuyeres Setups}

For different number and arrangement of bottom-blown gas tuyeres, simulation was used to investigate the flow pattern, the distribution of gas particles and the agitation of the slag particles. In the paper, the slag density was $0.33 \mathrm{~g} \mathrm{~cm}^{-3}$ in the water model at normal temperature, and the initial thickness of slag layer was $9 \mathrm{~cm}$. The simulation conditions were set as follows: gas flow rate was $2000 \mathrm{~cm}^{3} \mathrm{~s}^{-1}$, the height of liquid above the bottom of the vessel was $40.5 \mathrm{~cm}$, and initial bubble diameter was $2.6 \mathrm{~cm}$. The numbers of bottom-blown gas tuyeres designed in this study were 3, 4, and 5 and their related positions are shown in Fig. 3.

As shown in Fig. 4, the flow pattern and the distribution 


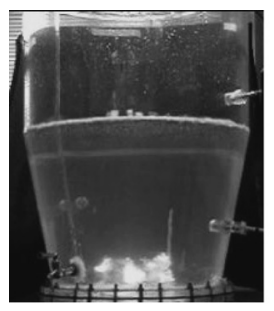

(a) $1.2 \mathrm{sec}$

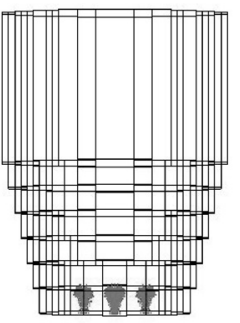

(a) $1.2 \mathrm{sec}$

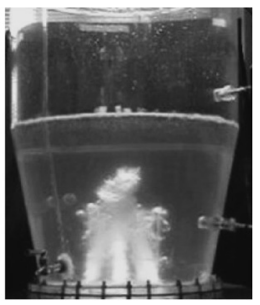

(b) $2.7 \mathrm{sec}$

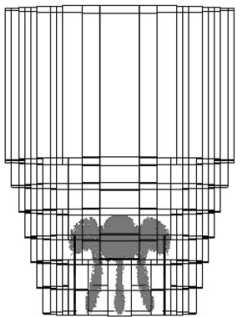

(b) $2.7 \mathrm{sec}$

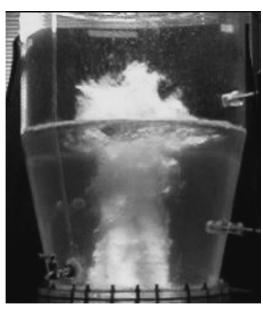

(c) $3.5 \mathrm{sec}$

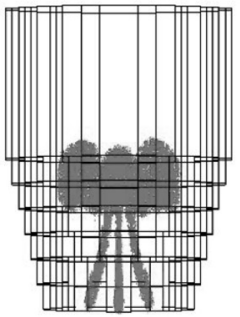

(c) $3.5 \mathrm{sec}$
Fig. 2. Comparison of simulation results and experimental results under $2000 \mathrm{~cm}^{3} / \mathrm{s}$ gas flow rate (front view of vessel using 5 tuyeres).

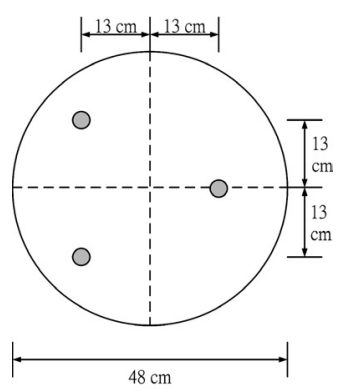

(a) 3 tuyeres setup

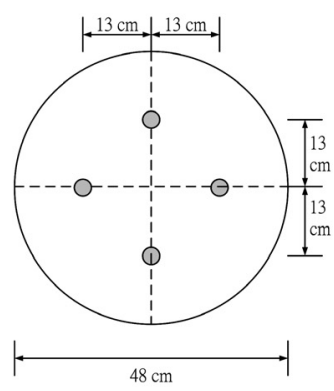

(b) 4 tuyeres setup

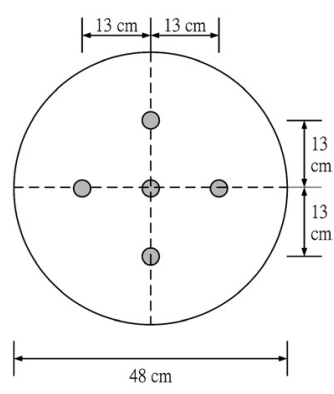

(c) 5 tuyeres setup

Fig. 3. Positions of different bottom-blown tuyeres setups (top view).
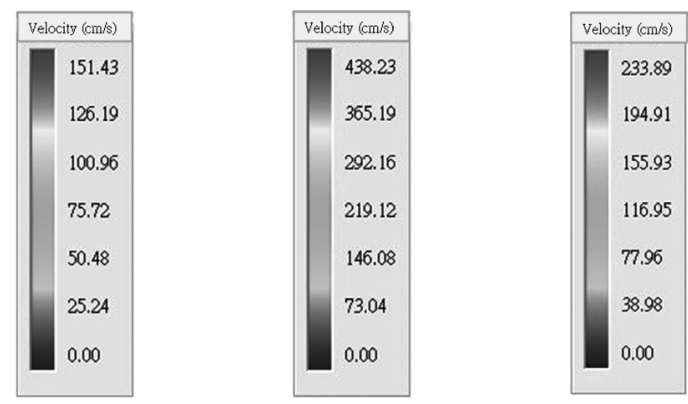

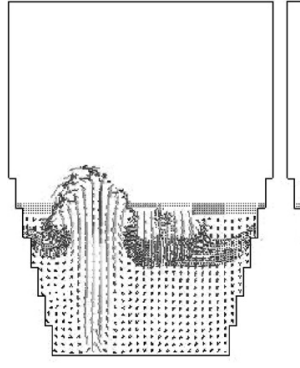

(3 tuyeres)

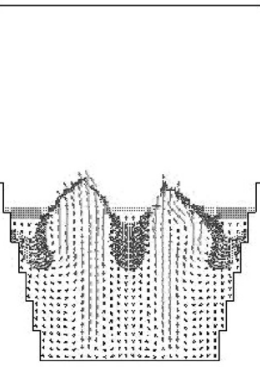

(4 tuyeres)

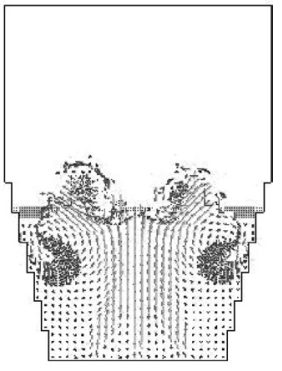

(5 tuyeres)
Fig. 4. Velocity profiles and slag particles distributions under different tuyeres setups (center cross section).

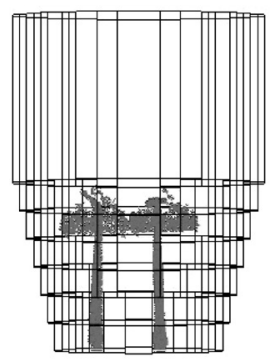

(3 tuyeres)

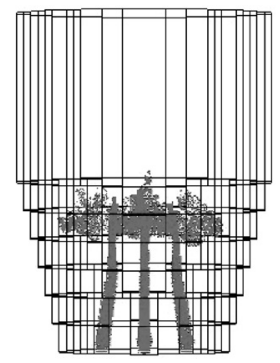

(4 tuyeres)

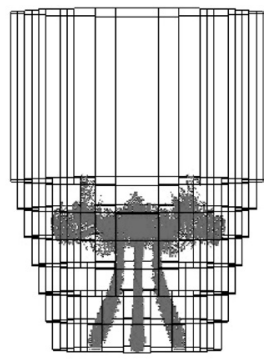

(5 tuyeres)
Fig. 5. Distributions of gas particles under different tuyeres setups (front view).

of slag at the center cross section are distributed asymmetrically in the 3 tuyeres case. In the 4 tuyeres case, some slag shows a low-velocity region in the center of the vessel. In the 5 tuyeres case, the flow pattern and the agitation of the slag is more violent than in the 3 and 4 tuyeres cases. As each tuyere has a fixed flow rate of $2000 \mathrm{~cm}^{3} \mathrm{~s}^{-1}$, each additional tuyere increases the total gas flow rate accordingly. According to Fig. 5, the flow pattern becomes more violent, the agitation of the liquid surface becomes greater, and the motion of gas bubbles also becomes more violent with an increasing number of tuyeres. According to Fig. 6, the agitation of the slag becomes more violent as the number of bottom-blown gas tuyeres increases.

\subsection{Gas/Liquid/Slag Interactions under Different Gas Flow Rates}

In order to investigate the flow pattern variation and mixing degree of multi-phase under different flow rate, the gas flow rate was set at 500,1200,2000 $\mathrm{cm}^{3} \mathrm{~s}^{-1}$ respectively and the surface of iron bath was set at $40.5 \mathrm{~cm}$ height above the bottom of the vessel. There were five bottom-blown gas tuyeres set at the bottom of vessel and the initial bubble diameter was $2.6 \mathrm{~cm}$. 


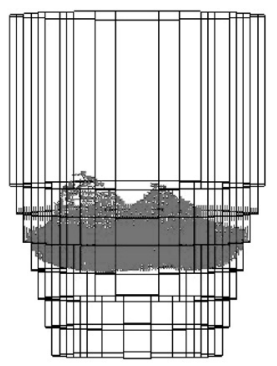

(3 tuyeres)

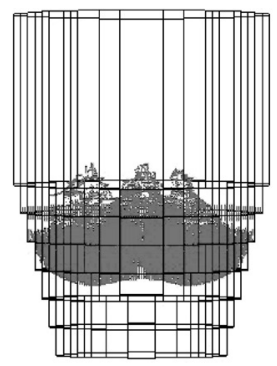

(4 tuyeres)

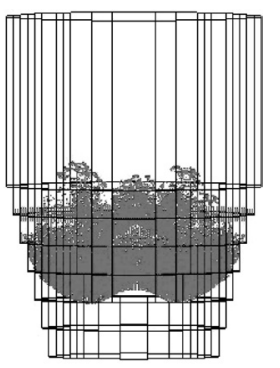

(5 tuyeres)

Fig. 6. Distributions of slag particles under different tuyeres setups (front view).
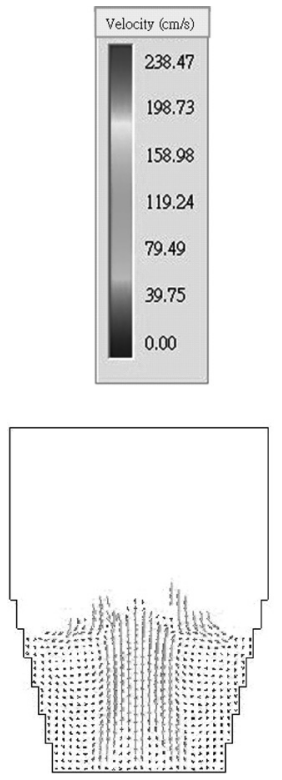

$\left(\mathrm{Q}=500 \mathrm{~cm}^{3} \mathrm{~s}^{-1}\right)$
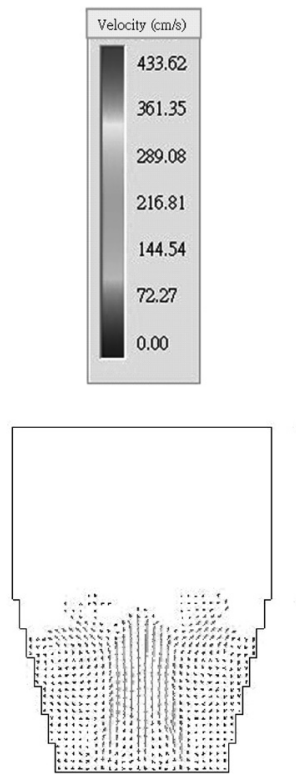

$\left(\mathrm{Q}=1200 \mathrm{~cm}^{3} \mathrm{~s}^{-1}\right)$
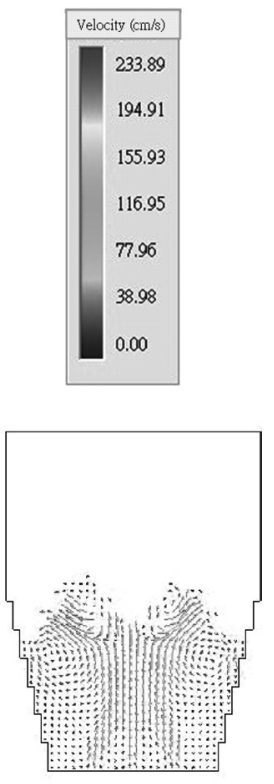

$\left(\mathrm{Q}=2000 \mathrm{~cm}^{3} \mathrm{~s}^{-1}\right)$

Fig. 7. Velocity profiles under different gas flow rates (center cross section).

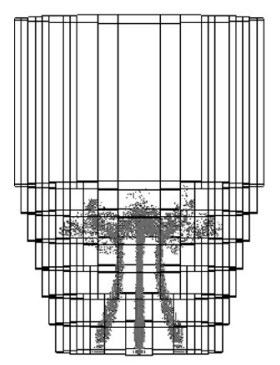

$\left(\mathrm{Q}=500 \mathrm{~cm}^{3} \mathrm{~s}^{-1}\right)$

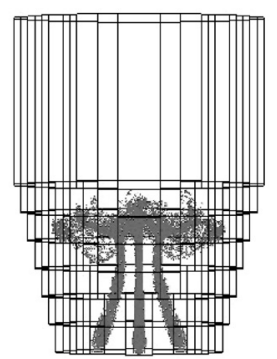

$\left(\mathrm{Q}=1200 \mathrm{~cm}^{3} \mathrm{~s}^{-1}\right)$

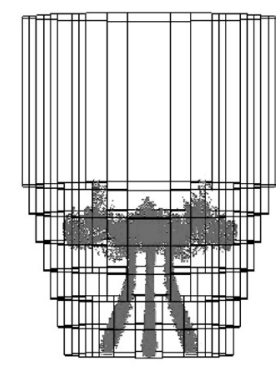

$\left(\mathrm{Q}=2000 \mathrm{~cm}^{3} \mathrm{~s}^{-1}\right)$

Fig. 8. Distributions of gas particles under different gas flow rates (front view).

As shown in Fig. 7, the flow pattern becomes more violent as the gas flow rate increases. The circular flow phenomenon near the wall and the region of low-velocity flow at the bottom of the model are easily identifiable. According to Figs. 8 and 9, the agitation of the liquid surface and slag become more violent, and the slag is carried much deeper into the liquid as the gas flow rate increases.
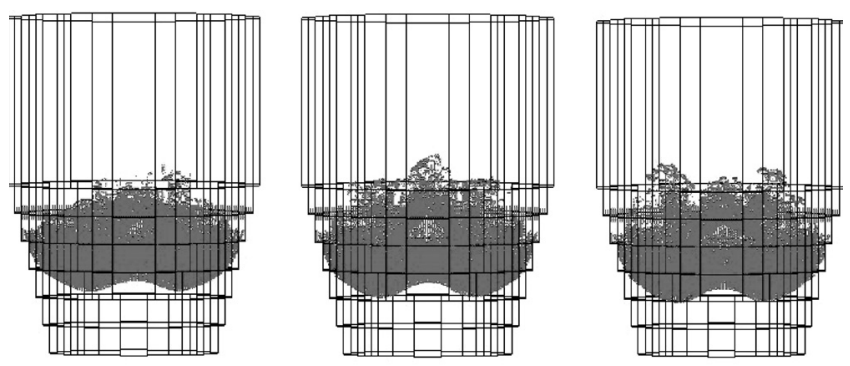

$\left(\mathrm{Q}=500 \mathrm{~cm}^{3} \mathrm{~s}^{-1}\right)$

$\left(\mathrm{Q}=1200 \mathrm{~cm}^{3} \mathrm{~s}^{-1}\right)$

$\left(\mathrm{Q}=2000 \mathrm{~cm}^{3} \mathrm{~s}^{-1}\right)$

Fig. 9. Distributions of slag particles under different gas flow rates (front view).
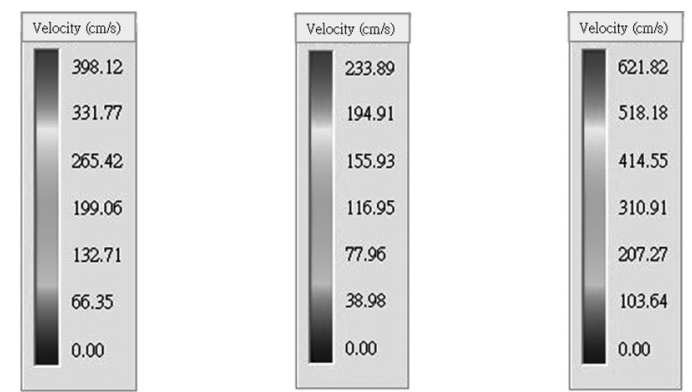

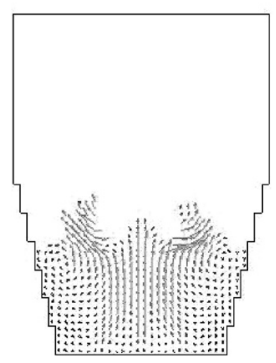

(a) $\mathrm{H}=32 \mathrm{~cm}$

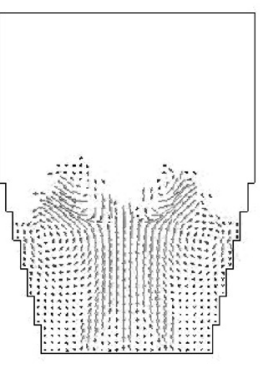

(b) $\mathrm{H}=40.5 \mathrm{~cm}$

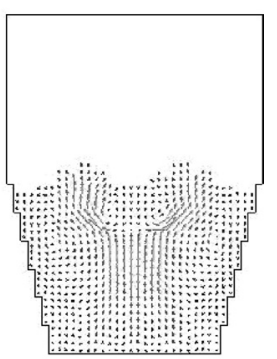

(c) $\mathrm{H}=48 \mathrm{~cm}$

Fig. 10. Velocity profiles under different height of liquid surface (center cross section).

\subsection{Gas/Liquid/Slag Interactions under Different Height of Liquid Surface}

For the understanding of flow pattern, the distribution of gas particles and the agitation of the slag under different height of liquid surface, the numerical simulation conditions were set as follows: the gas flow rate was $2000 \mathrm{~cm}^{3} \mathrm{~s}^{-1}$, the initial bubble diameter of bubble was $2.6 \mathrm{~cm}$, and five bottom-blown gas tuyeres were located. The heights of liquid above the bottom of the furnace were $32 \mathrm{~cm}, 40.5 \mathrm{~cm}$, and $48 \mathrm{~cm}$.

As shown in Fig. 10, the flow pattern becomes smaller as the height of liquid surface increases. It's owing to the effect that momentum transfer becomes smaller as the volume of liquid becomes larger under the same gas blowing rate. As shown in Fig. 11, the rising height of gas bubbles increases and the agitation of the liquid surface become smaller as the height of liquid surface increases. According to Fig. 12, the agitation of the slag becomes smaller and it is carried less deep into the liquid as the height of liquid surface increases. 

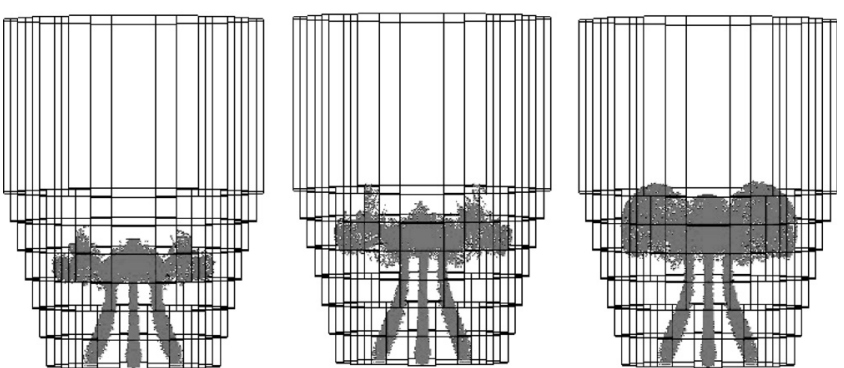

(a) $\mathrm{H}=32 \mathrm{~cm}$

(b) $\mathrm{H}=40.5 \mathrm{~cm}$

(c) $\mathrm{H}=48 \mathrm{~cm}$

Fig. 11. Distributions of gas particles under different height of liquid surface (front view).

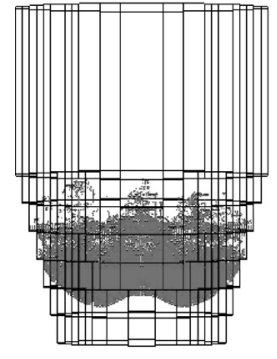

(a) $\mathrm{H}=30 \mathrm{~cm}$

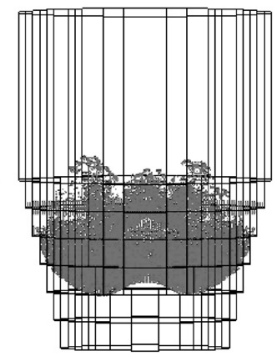

(b) $\mathrm{H}=40.5 \mathrm{~cm}$

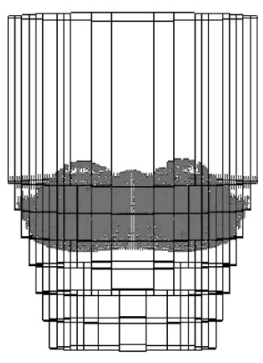

(c) $\mathrm{H}=48 \mathrm{~cm}$
Fig. 12. Distributions of slag particles under different height of liquid surface (front view).

\subsection{The Results of Gas-Liquid-Slag Phase Numerical Simulations for Different Diameter of Gas Bubble}

For different diameter of gas bubble, the simulation software was used to investigate the flow pattern, the distribution of gas particles, and the agitation of slag. The numerical simulation conditions were set as follows: the gas flow rate was $2000 \mathrm{~cm}^{3} \mathrm{~s}^{-1}$, the initial diameters of bubbles were $1.6 \mathrm{~cm}, 2.6 \mathrm{~cm}$ and $2.8 \mathrm{~cm}$, the simulated number of bottom-blown gas tuyere was 5 , the height of liquid above the bottom of the furnace was $40.5 \mathrm{~cm}$.

As shown in Fig. 13, under a gas flow rate of $2000 \mathrm{~cm}^{3} \mathrm{~s}^{-1}$, the flow pattern becomes larger as the diameter of gas bubble increases. According to Figs. 14 and 15, the agitation of liquid surface and slag become more violent and the slag is carried deeper into the liquid as the diameter of gas bubble increases.

\section{Conclusions}

A mathematical model for the simulation of multi-phase flows in the direct smelting reduction vessel has been developed in this study. The interaction among gas bubbles, iron bath and molten slag can be directly observed from the simulated results, which allows the engineer to gain better insight to the flow pattern and mixing/reduction efficiency in the direct smelting reduction process.

The developed system was applied to analyze the flow behavior in the $60 \%$ reduced experimental smelting reduction vessel. As each tuyere has a given flow rate, flow pattern, agitation of liquid surface, and slag become more violent with an increasing number of tuyeres. Under conditions of given gas tuyere setups and liquid bath volume, its related flow pattern and the agitation of the liquid surface be-
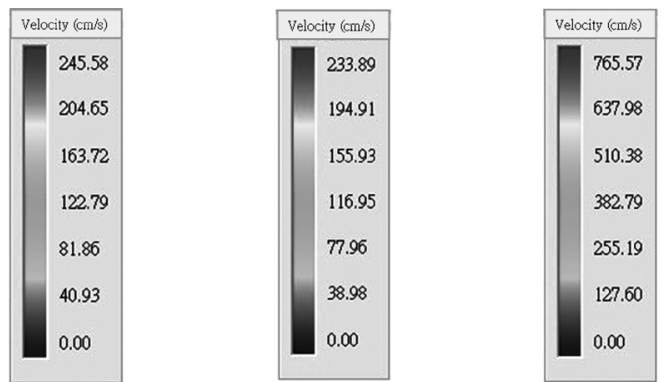

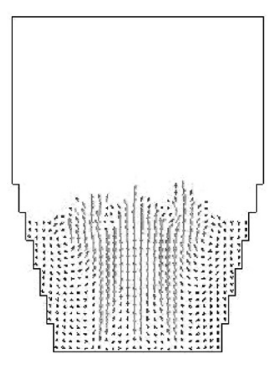

(a) $\mathrm{d}=1.6 \mathrm{~cm}$

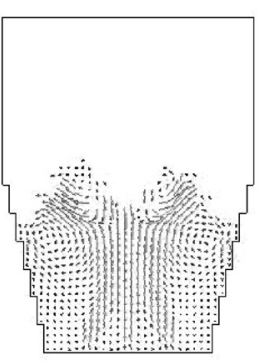

(b) $\mathrm{d}=2.6 \mathrm{~cm}$

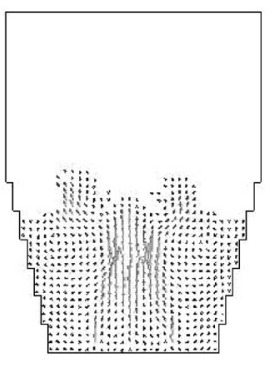

(c) $\mathrm{d}=2.8 \mathrm{~cm}$
Fig. 13. Velocity profiles under different diameter of gas bubble blowing (center cross section).

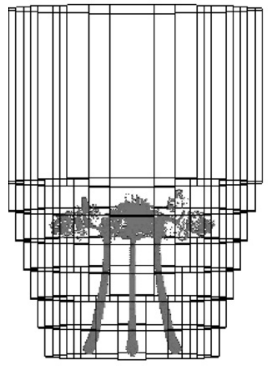

(a) $\mathrm{d}=1.6 \mathrm{~cm}$

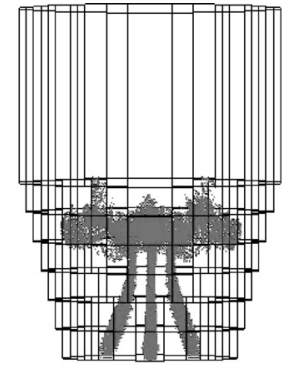

(b) $\mathrm{d}=2.6 \mathrm{~cm}$

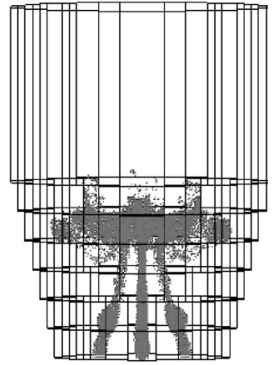

(c) $\mathrm{d}=2.8 \mathrm{~cm}$
Fig. 14. Distributions of gas particles under different diameter of gas bubble blowing (front view).

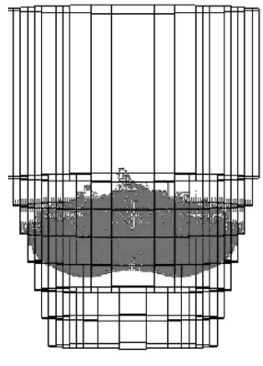

(a) $\mathrm{d}=1.6 \mathrm{~cm}$

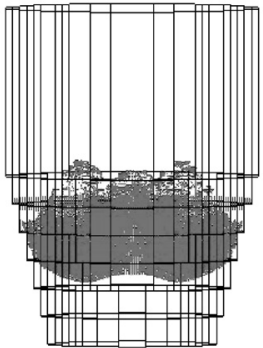

(b) $\mathrm{d}=2.6 \mathrm{~cm}$

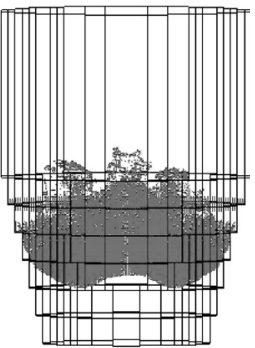

(c) $\mathrm{d}=2.8 \mathrm{~cm}$
Fig. 15. Distributions of slag particles under different diameter of gas bubble blowing (front view).

come more violent, and therefore slag is carried much deeper into the liquid as the gas flow rate increases. When the volume of liquid bath is getting larger, its momentum transfer efficiency is gradually worse if other conditions are fixed. As diameter of bubble-blowing is getting larger, the results show better mixing efficiency in the system.

\section{Acknowledgement}

The authors would like to thank the National Science Council of Taiwan for financially supporting this research 
ISIJ International, Vol. 46 (2006), No. 8

under the research grant of NSC 94-2216-E-006-011.

\section{REFERENCES}

1) R. J. Fruehan: Iron Steelmaker, 30 (2003), 48.

2) J. Feinman: Iron Steel Eng., 76 (1999), 75.

3) D. Mazumdar and R. I. L. Guthrie: ISIJ Int., 35 (1995), 1.

4) M. B. Goldschmit and A. H. Coppola Owen: Ironmaking Steelmaking, 28 (2001), 337.
5) M. Madan, D. Satish and D. Mazumdar: ISIJ Int., 45 (2005), 677.

6) S. M. Pan, J. D. Chiang and W. S. Hwang: J. Mater. Eng. Perform., 8 (1999), 236.

7) P. Liovic, J. L. Liow and M. Rudman: ISIJ Int., 41 (2001), 225.

8) C. W. Hirt, B. D. Nichols and R. S. Hotchkiss: Technology Report LA-8355, Los Alamos Scientific Laboratory, New Mexico, (1980).

9) D. L. Youngs: Numerical Methods for Fluid Dynamics, ed. by K. W. Morton, Academic Press, New York, (1982), 273. 